\title{
Predicting land use change on a broad area: Dyna-CLUE model application to the Litorale Domizio-Agro Aversano (Campania, South Italy)
}

\author{
Stefania Pindozzi, ${ }^{1}$ Elena Cervelli, ${ }^{2}$ Pier Francesco Recchi, ${ }^{1}$ Alessandra Capolupo, ${ }^{2}$ Lorenzo Boccia ${ }^{3}$ \\ ${ }^{1}$ Department of Agricultural Sciences, University of Naples Federico II, Portici (NA); ${ }^{2}$ Interdepartmental Research \\ Centre for Environment, I.R.C.Env, Naples; ${ }^{3}$ Department of Architecture, University of Naples Federico II, Portici \\ (NA), Italy
}

\begin{abstract}
The long-standing awareness of the environmental impact of land-use change (LUC) has led scientific community to develop tools able to predict their amount and to evaluate their effect on environment, with the aim supporting policy makers in their planning activities. This paper proposes an implementation of the Dyna-CLUE (Dynamic Conversion of Land Use and its Effects) model applied to the Litorale Domizio-Agro Aversano, an area of Campania region, which needs interventions for environmental remediation. Future land use changes were simulated in two different scenarios developed under alternative strategies of land management: scenario 1 is a simple projection of the recent LUC trend, while scenario 2 hypothesises the introduction of no-food crops, such as poplar (Populus nigra L.) and giant reed (Arundo donax L.), in addition to a less impactful urban sprawl, which is one of the main issues in the study area. The overall duration of simulations was 13 years, subdivided into yearly time steps. CORINE land cover map of 2006 was used as baseline for land
\end{abstract}

Correspondence: Stefania Pindozzi, Department of Agricultural Science, University of Naples Federico II, via Università 100, 80055 Portici (NA), Italy.

Tel. +39.081.2539128.

E-mail: stefania.pindozzi@unina.it

Key words: Land use change modelling; Dyna-CLUE; scenario analysis; model calibration; Kappa statistics.

Funding: the work was funded by the European Commission under the LIFE+ Programme, in the framework of the LIFE11/ENV/IT/275ECOREMED - Implementation of EcoCompatible Protocols for Agricultural Soil Remediation in Litorale Domizio-Agro Aversano NIPS. More information on the project is available on the ECOREMED website: www.ecoremed.it

Conflict of interest: the authors declare no potential conflict of interest.

Received for publication: 29 December 2016.

Accepted for publication: 29 April 2017.

CCopyright S. Pindozzi et al., 2017

Licensee PAGEPress, Italy

Journal of Agricultural Engineering 2017; XLVIII(s1):657

doi:10.4081/jae.2017.657

This article is distributed under the terms of the Creative Commons Attribution Noncommercial License (by-nc 4.0) which permits any noncommercial use, distribution, and reproduction in any medium, provided the original author(s) and source are credited. use change detection in the study area. Competition between different land use types is taken into account by setting the conversion elasticity, a parameter ranging from 0 to 1 , according to their capital investment level. Location suitability for each land use type is based on logit model. Since no actual land use already exists for the alternative crops investigated in scenario 2, a suitability map realised through a spatial multicriteria decision analysis was used as a proxy for its land use pattern. The comparison of the land use in 2012 and scenario 1, evaluated through the application of Kappa statistics, showed a general tendency to expansion of built-up areas, with an increase of about 2400 ha $(1.5 \%$ of the total surface), at the expense of agricultural land and those covered by natural vegetation. The comparison of the land use in 2012 and scenario 2 showed a less significant spread of built-up areas, affecting approximately 750 ha $(0.5 \%$ of the total surface). Moreover, the introduction of alternative crops on about 10,000 ha, that is $6.8 \%$ of the total surface, would result in a significant decrease of arable land and a lower decrease of permanent crops, respectively equal to 6800 ha and 2900 ha.

This work highlighted the importance and the potential of predicting land-use change models as valid tools supporting decisions, especially in those regions needing interventions aimed to environmental remediation, as in the case study examined in this paper.

\section{Introduction}

Land use change (LUC) is a crucial issue for the environmental science, since it is one of the main causes of most environmental problems, such as global warming, loss of biodiversity, alteration of biogeochemical cycles and soil erosion (Agarwal et al., 2002; Murray-Rust et al., 2014; Zhang et al., 2015). A rational land use planning is therefore essential for a sustainable exploitation of natural resources. In such a context land use modelling can be an important tool for creating different scenarios of future LUC under alternative strategies of development (Veldkamp and Lambin, 2001), in order to assess their effects at different scales. Basically the aim of the research in land use change modelling is to provide an effective decision support tools for the environment, economic and social development policies (Verburg et al., 2002). Given the complexity of dynamics and the factors involved in, the reliability of a model is based mainly on its scientific rigorousness (Agarwal et al., 2002). In order to use models for land use change assessment, calibration and validation of the model itself are required (Hewitt and Escobar, 2011). Models can be calibrated and validated in several ways since there are no standards. According to a recent study the most frequently used procedure for calibration is statistical one, whereas the location accuracy is 
the most used as validation procedure (Van Vliet et al., 2016).

Campania region is one of the most important regions in Italy for agricultural products but it is recently facing a big challenge for being suspected of a wide contamination, especially in the so called Land of Fires (Capolupo et al., 2015; Cervelli et al., 2016). Illegal spills and not authorised dumps have been discovered patchy in all the area, but actual contamination has still to be demonstrated. Nevertheless if nothing would be accomplished to restore the reputation of this area in the next years, main consequence would be the progressively abandonment of agricultural lands and replacement with new urban settlements.

The area is now under study, within the LIFE ECOREMED European project (www.ecoremed.it), aimed at bioremediation of agricultural soils, with the introduction of plants identified as phytoextractors, waiting for decontamination of soils. The project will end with the implementation of a protocol of bioremediation to be applied widely in the study area that is a site of regional interest (SIR) named Litorale Domitio Flegreo-Agro Aversano. Consequently new crops will replace current crops, namely poplar, giant reed and eucalyptus, in areas individuated as suitable of change (Cervelli et al., 2016), to be recycled with energy and matter recovery purpose (Giudicianni et al., 2017; www.ecoremed.it).

During recent years several attempts were made in the study area, trying to assess the spatial allocation of energy crops, introduced to reduce soil risk erosion (Pindozzi et al., 2013) or to remediate contaminated soils (Cervelli et al., 2016), basing on deterministic or probabilistic approach, respectively. In any case it was not possible to establish a time horizon of change, and which areas will change for first. The aim of this paper is the application of a prediction land use model, the Dyna-CLUE model (Dynamic Conversion of Land Use and its Effects) (Verburg and Overmars, 2009), after its validation, in a large area, never studied before with this approach, to assess what will happen if current trend will last for the next 13 years, from 2012 to 2025 , or in alternative if new crops and new environmental policies would be applied. As DynaCLUE model is not able to predict spatial allocation of energy crops, because does not have a separate class for them (Hellmann and Verburg, 2011), their allocation was based on a suitability map, sorted out from the application of spatial multi criteria decision analysis (Malczewski, 2006), introducing the specific class.

The methodology proposed is strongly dependent from the accuracy of the land use/cover map used as baseline, and on a detailed knowledge of the area. Moreover the methodology is useful to improve the awareness about the actual risk of the agricultural areas of being abandoned or transformed in urban areas, which expansion seems uncontrolled. On the other hands new environmental policy will result in new opportunity of economic growth for the study area, reducing agricultural abandonment and urban sprawl. For these reasons this study deepens the knowledge of land use dynamics towards new environmental friendly policies and poses the basis to conduct subsequent impact evaluation (Cervelli et al., 2017).

\section{Materials and methods}

\section{Overview of methodology}

The use of land use change models are main tools for analysing the causes and consequences of land use changes, providing new insights in the assessment of LUC impacts on ecosystems and supporting land use policy and management (Luo et al., 2010). Studies devoted to LUC analysis are recently applying computational approach to be performed (Parker et al., 2003) improving results quality. LUC is determined by the interaction between biophysical and human factors in a spatial and temporal context, therefore predicting models must take into account such elements. If scale of a model essentially provides information about space, time and agents, complexity represents its ability to consider driving forces determining the LUC (Agarwal et al., 2002).

The analysis of the driving forces is a crucial step in the development of a predicting model, as it allows determining the factors involved in the LUC, such as natural resources, climate, topography of the area, demographics, socioeconomic conditions, etc. The weight of driving forces in determining LUC is depending on their nature and it can be estimated through statistical approach. The dynamic approach in modelling, such as the one used in DynaCLUE, provides for the integration of statistical methods with different principles, which generally define a better consideration of the driving forces. Beyond approaches, almost all models are based on the use of geographic information systems.

Dyna-CLUE consists of four modules: land-use requirements, which is the amount of land devoted to change and it is estimated according to considerations about the demographic and/or socioeconomic context; location characteristics, representing local suitability to a specific land use and it is determined by different driving forces; spatial policies and restrictions, which are the areas in which LUC is restricted by law; finally, land use type specific conversion settings, which are determined by the specific characteristics of each land use type (Verburg et al., 2002; Verburg and Veldkamp, 2004). All data needed for the application of the model to the study area (the site of regional interest called Litorale Domitio-Flegreo and Agro Aversano) were fully provided by the University of Naples Federico II, one of the partners of the LIFE ECOREMED European project involved in the implementation of the bioremediation protocol. This last has been realised providing the introduction of specific no-food crops with high attitude to phytoextraction. Therefore the development of the model led to the creation of two different scenarios up to 2025: the first one (scenario 1) is a simple projection of recent LUC trends in the absence of specific environmental policies, while the second one (scenario 2) assumes a possible evolution of the territory as a result of interventions focused on phytoremediation. Scenarios of change were aimed at matching principles of the European directives concerning protection of the territory, such as: desirability of a rationale and orderly development of urban and suburban territory minimising soil consumption; protection of territory physical integrity and cultural identity through the landscape-environmental and historical-cultural resources valorisation, conservation of ecosystems, revitalisation of existing settlements and compromised sites restoration; improvement of inhabited centres healthiness and comfort; strengthening regional and local economic development in terms of sustainability; protection and development of the agricultural landscape and associated productive activities; protection and development of the sea-land landscape and related productive and tourism activities.

\section{Study area}

The study area is the SIR of Litorale Domitio-Flegreo and Agro Aversano, located in Campania region, South of Italy (Figure 1). The area extends for $157,000 \mathrm{ha}$; it is divided in 77 municipalities, with a population of about 1.4 million of inhabitants. Study area is crossed by Volturno river. The elevation ranges from sea level to about 972 m.a.s.l. (meters above sea level) with a mean of 75 m.a.s.l. Geomorphology of the study area, as well as its land- 
scape, is highly heterogeneous, with wide costal planes, a quite high inland, promontories and volcanoes. Despite human activity affects rather deeply all the area, especially in the Volturno valleys, where urban, industry and intensive agriculture areas intertwine in a typical agrarian landscape, there are few important natural sites characterised by broad-leaved forests, natural grasslands or maquis, mainly in the northern part of the area. Campania Region recently classified the study area as SIR downgrading it from the previous classification national interest priority sites responding to the definition of part of the national territory delimited from the site characterisation in terms of presence of pollutants (quantity and quality) and environmental impacts on the adjacent areas (Cervelli et al., 2016).

\section{The Dyna-CLUE model}

The scenarios were created using the Dyna-CLUE model (Verburg and Overmars, 2009; Hellmann and Verburg, 2011;
Shoyama and Yamagata, 2014). In the Dyna-CLUE modelling framework the allocation of different land use types at grid cell level is based on a combined effect of location suitability, agents' competitiveness and factors related to political and socioeconomic context (Shoyama and Yamagata, 2014).

Competition between different land use types is taken into account by setting the conversion elasticity, a parameter ranging from 0 (easy conversion) to 1 (difficult conversion), according to their capital investment level (Verburg et al., 2002; Verburg and Veldkamp, 2004). Lower values were assigned to low capital land uses, such as arable land (0.2), while higher values were assigned to high capital land uses, such as urban fabric (1). Since not every kind of land use changes is logically possible, for example it is very unlikely that any built-up area is converted into an agricultural one, or just that grassland is converted into forest within reasonable time, allowed land use transition sequences must be specified in a conversion matrix (Verburg and Veldkamp, 2004).

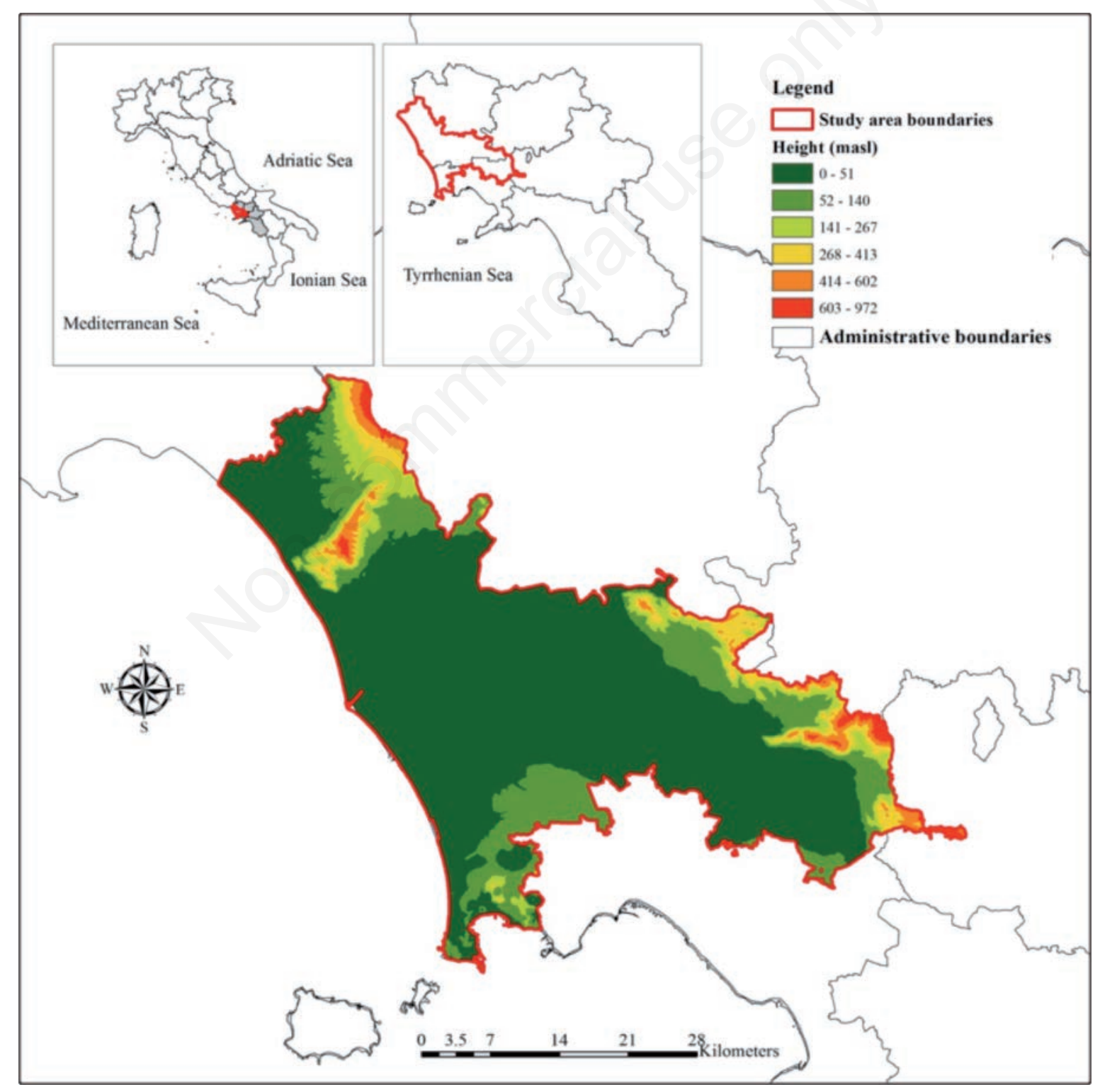

Figure 1. Study area. 
Location suitability for each land use type, defined as location characteristic, is based on a statistic analysis aimed at estimating relations between a specific land use and the driving factors thought to be relevant in its determination. A logit model is used to define the probability for the occurrence of each land use type on each of the grid cells, according to the following relation:

$\operatorname{Logit}\left(\mathrm{P}_{\mathrm{i}}\right)=\ln \left(\mathrm{P}_{\mathrm{i}} / 1-\mathrm{P}_{\mathrm{i}}\right)=\beta_{0}+\beta_{1} \mathrm{X}_{1, \mathrm{i}}+\beta_{2} \mathrm{X}_{2, \mathrm{i}} \ldots+\beta_{\mathrm{n}} \mathrm{X}_{\mathrm{n}, \mathrm{i}}$

where $\mathrm{P}_{\mathrm{i}}$ is the probability for the occurrence of the considered land use on the location $\mathrm{i}, \mathrm{X}_{1,2 \ldots \mathrm{n}}$ are the values of the driving factors, while $\beta_{0,1,2 \ldots n}$ are coefficients estimated by logistic regression using the actual land use pattern as dependent variable (Verburg and Veldkamp, 2004). The driving forces analysed are divided in geophysical and socio-economic factors. Regarding the geophysical factors, elevation, slope, soil erosion and soil characteristics were taking into account. For the socioeconomic factors pollutants concentrations and accessibility to main facilities, namely distance from the sea, streams, protected areas, urban areas and main roads were considered. As not all of the variables have necessarily an influence on the spatial allocation of every different land use types, a stepwise procedure was used in the regression analysis to select only the driving factors showing a relevant effect on land use pattern (Verburg et al., 2002). The 2006 CORINE land cover (CLC) map was taken as a reference for the analysis. Since no actual land use already exists for the phytoremediation/energy crops investigated in the scenario 2, a suitability map realised through a multicriteria-spatial decision support systems (Malczewski, 2006) was used as a proxy for its land use pattern (Hellmann and Verburg, 2011). Specifically multi-criteria analysis was performed according to the following five steps: i) criteria individuation, sorted out from the environmental characterisation of the study area performed within the framework of the LIFE ECOREMED project and including data from soils, air, water and land system as reported in Cervelli et al., 2016. For each criterion a raster dataset was generated, $20 \times 20 \mathrm{~m}$ of resolution; ii) criteria tree development; criteria were organised as factors (with an intrinsic attitude towards change) or constraints (areas to be excluded from the analysis); iii) criteria standardisation; in order to perform comparison among different criteria, standardisation is needed for which all raster dataset are reported in the same range of values going from 0 to 1 ; iv) weighting of criteria; the corresponding relative importance weights have been assigned to each map. The weight mapping was performed according to the ANP technique (Saaty, 2005) and by the pairwise comparison checked by a panel of experts, constituted by scientists belonging to the LIFE ECOREMED project; v) suitability map creation; representing a final raster dataset identifying areas more susceptible to land use change. Steps from three to five have been carried out with ILWIS 3.8 software (Informer Technologies, Inc., Madrid, Spain).

The goodness of fit of the logistic regression was evaluated using the relative operating characteristic method (ROC) (Pontius and Schneider, 2001; Verburg et al., 2002; Verburg and Veldkamp, 2004; Shoyama and Yamagata, 2014) by overlaying the probabilities maps of each land use type with their 2012 actual pattern. In such a way spatial distribution of each land use type can be validated according to its ROC values, ranging from 0.5 for a complete random allocation, to 1 for a perfect fit (Pontius and Schneider, 2001).

The total amount of future land use changes in purely quantitative terms (demand) is defined at aggregate level before the start of the simulation, for each time steps, according to the different contexts of each scenario (Verburg et al., 2002; Verburg and
Veldkamp, 2004). Demand for the trend scenario was calculated as a projection of the trend observed during the period 2006-2012. Future land use requirements were not corrected for changes in population. The model takes into account population density in the study area as one of driving forces analysed. Specifically population is slightly decreasing in Naples province (southern part of study area), and is moderately increasing for Caserta province (northern part of study area) according to census data. Besides of the detailed changes of population trends in each municipality, the whole study area is interested by a general urban sprawl and land infrastructure (Pindozzi et al., 2016).

Land use changes requirements for phytoremediation crops scenarios were related to targets thought to be reliable as a consequence of the implementation of LIFE ECOREMED project's protocol. Once all the parameters are set, an iterative process allocates the different land use types, according to their driving forcesdependent probabilities on each of the grid cells, until their total amount meets the land use requirements fixed for each different scenario, in a combination of a typical bottom-up with a top-down approach (Verburg and Overmars, 2009; Murray-Rust et al., 2014).

\section{Spatial policies and restrictions}

The model allows the exclusion of areas subject to legislative constraints in land management by imposing restrictions on the change of land use within specific areas of interest. References for delineating such areas were derived from regional territorial plan (PTR; 2006, available from: http://www.sito.regione. campania.it/PTR2006/PTRindex.htm) of Campania Region, particularly for aspect recalling the European Landscape Convention. Zones excluded from the iterations of the model are the protected areas, such as parks, reservoirs, wetlands and sites of natural or cultural interest. Informative layers were derived from the abovementioned PTR. The total extent of the study area is introduced in the model as binary ASCI file called region. Areas within the restrictions are characterised by cells value -9998 , whereas cells where LUC is allowed, have 0 value.

\section{Land use change and scenario analysis}

Future land use changes were simulated in 2 different scenarios developed under alternative strategies of land management. The first one (trend scenario) represents a simple projection of the recent trends. The second scenario (phytoremediation scenario) simulated the introduction of phytoremediation crops, suitable also as energy crops, to restore soils from contamination or reduction of fertility (Fiorentino et al., 2017). Both scenarios were started from last update of land cover derived from the CLC III level for the year 2012. The overall duration of simulations was 13 years, from 2012 to 2025 , subdivided into yearly time steps.

CLC map of 2006 was considered as the reference map, that is the map considered as baseline for model validation. These maps result from analysis and digitalisation of Landsat photos, with a nominal scale of 1:100,000, a minimum mapping unit of 25 ha and a change detection threshold of 5 ha (EEA, 2006). Then CLC classes were grouped into four macro-classes based on the first and second level of CLC. The four classes analysed are the following:

Natural areas (class 0): all areas within the classes 3, 4 and 5 of first level of CLC, including sparsely vegetated areas, bare soil, wetlands and water bodies. Class 0 appears to be very heterogeneous, nevertheless the classes merged together cover a very small surface compared to whole study area. Moreover wetlands and water bodies are not subject to LUC as they entirely fall in the protected areas (constraints area). 
- Permanent crops (class 1): this class refers to the classes 2.2 (permanent crops) and 2.4.1 complex cultivation patterns of the second and third level of CLC, respectively.

- Arable lands (class 2): This class is the union of the class 2.1 (arable land) and 2.3 (pasture) of the second level of CLC.

- Urban areas (class 3): corresponding to the first class of the first level of CLC.

Only for scenario 2 another class was added to the others, that is the no-food crops (class 4).

Arable lands and permanent crops are not merged together, distinguishing from arboreal and herbaceous vegetation, basing on the considerations that these typologies of crops have different conversion elasticity.

\section{Model validation and map comparison}

Validation of the model was performed through a historical validation, for which the comparison is performed between predicted land use map and the observed one, in the same period, 2012 for the present study (Rykiel, 1996; Verburg et al., 2002). In order to validate the model, it was also ran for the period 2006-2012 and then, simulated map of 2012, was compared with observed one of the same year. The comparison has been performed through the use of open source Map Comparison Kit (MCK software) (Visser and De Nijs, 2006; Hewitt and Escobar, 2011) using Kappa simulation algorithm. This algorithm is able to express the degree of agreement in relation to the amount of change within the individual classes basing on the value of a coefficient. The $K_{\text {Simulation }}$ coefficient arises from the product of two factors, $K_{\text {Transition, and }}$ $K_{\text {TransLoc, }}$, representing the agreement in terms of categories change (i.e., what has changed) and the similarity in terms of allocation (i.e., in what has changed) respectively. The $K_{\text {Simulation }}$ coefficient can range from -1 to 1 . Although scores above 0 indicate a positive compliance of the model, it is better to get closer to 1, which indicates a perfect agreement of the model (van Vliet et al., 2011). However it is possible that a model gives a good agreement quite all the extent of the actual map used for the validation. This issue is maybe devoted to the current CLC accuracy, still about $85 \%$ (Panagos et al., 2015). In areas where $K_{\text {Simulation }}$ coefficient was not so high, CLC level of reliability was improved by integrating information from different data sources, such as the LUCAS surveys (Gallego, 2002), aerial photos and comparison with previous classification provided by the agricultural land use map [Carta degli Usi Agricoli del Suolo (CUAS), 2009: http://sit.regione.campania.it/portal] from Campania region. The comparison has the main aim of explain the not agreement and so to take into account the grades of similarity between pairs of cells in two maps. At this aim, the Fuzzy Kappa map comparison was also used. The Fuzzy Kappa is based on a cell-by-cell map comparison, which entails the neighbourhood of a cell in a value between 0 (fully distinct) and 1 (fully identical) to express similarity of that cell. The value of 0.5 can be deduced as considerably similar (Hagen, 2003).
After model validation, the comparison between predicted land use map and the starting map in both scenarios was performed with Kappa statistic algorithm. The contingency table was then derived and land use classes changes in hectares were estimated (Pindozzi et al., 2016).

The reliability of the model to predict spatial allocation of class 4 of scenario 2 (i.e., energy crops) was performed with per catego$r y$ algorithm of MCK software, comparing class 4 to total extension of areas suitable for LUC (the so called fringe areas from Cervelli et al., 2016) sorted out from the suitability map.

\section{Results}

\section{Regressions analysis and location suitability}

The highest ROC value was found for natural areas (0.904). For the other classes (permanent crops, arable lands and urban areas) lower ROC values were observed, ranging from 0.7 to 0.8 , considered already sufficient to demonstrate the goodness of the regression.

\section{Model validation and map comparison}

Figure 2 shows simulation results from Dyna-CLUE application, for the year 2012 compared to initial map of 2006 and observed map of 2012 from CLC. The overall value of $K_{\text {Simulation }}$ values for the comparison is 0.872 , meaning that the model is enough capable to simulate LUC for the study area. Nevertheless an investigation for each land use class is needed. $K_{\text {Simulation }}$ values for each land use class are reported in Table 1 . The $K_{\text {Simulation }}$ value is affected by the lower value of $\mathrm{K}_{\text {TransLoc }}$ (similarity in terms of allocation) for the two classes belonging to agricultural areas, namely permanent crops and arable land. This might be explained by misleading photointerpretation of satellite images for producing CLC maps (EEA, 2006). Thus, maybe the model confuses the two agricultural areas due to their similarity. The Fuzzy Kappa was introduced to have the overall similarity of the two maps (Hagen, 2003). The K Kuzzy calculated assuming that the two classes arable lands and permanent crops can be confused (Visser and Nijs, 2006), grow up to 0.9 (Figure 3).

Finally from the comparison performed through per category algorithm, there is a clear overlap between areas allocated to class 4 by Dyna-CLUE and the fringe areas. In this case, about $87 \%$ of the total 9985 ha of alternative crops foreseen in scenario 2 is overlapped to fringe areas highlighted from multi-criteria decision analysis.

\section{Scenario 1}

Scenario 1 is based on the trend of the past land use (Verburg and Veldkamp, 2004; Shoyama and Yamagata, 2014). All land use classes are supposed to grow at the same rate of hectares per years

Table 1. Kappa simulation values for each land use class analysed obtained from the comparison of observed map of 2012 and simulated for the same year.

\begin{tabular}{lcccc} 
& Natural areas & Permanent crops & Arable land & Urban areas \\
Kappa Simulation & 0.964 & 0.790 & 0.776 & 0.960 \\
Kappa TransLoc & 0.969 & 0.791 & 0.776 & 0.964 \\
\hline Kappa Transition & 0.995 & 0.998 & 0.999 & 0.996 \\
\hline
\end{tabular}




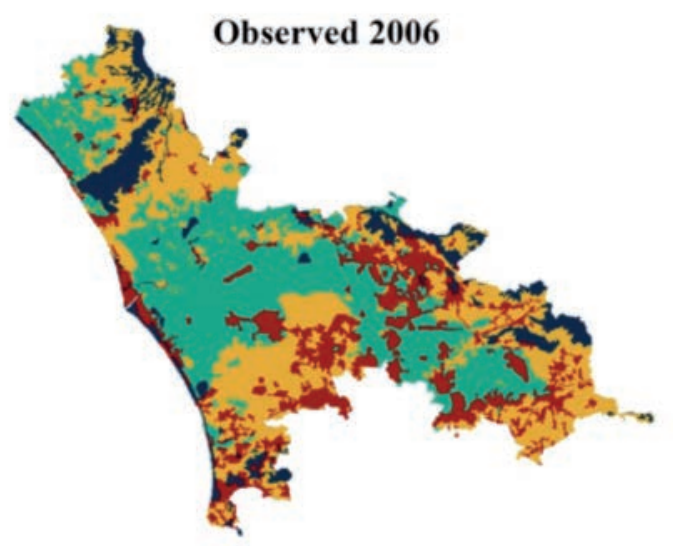

\section{Legend}
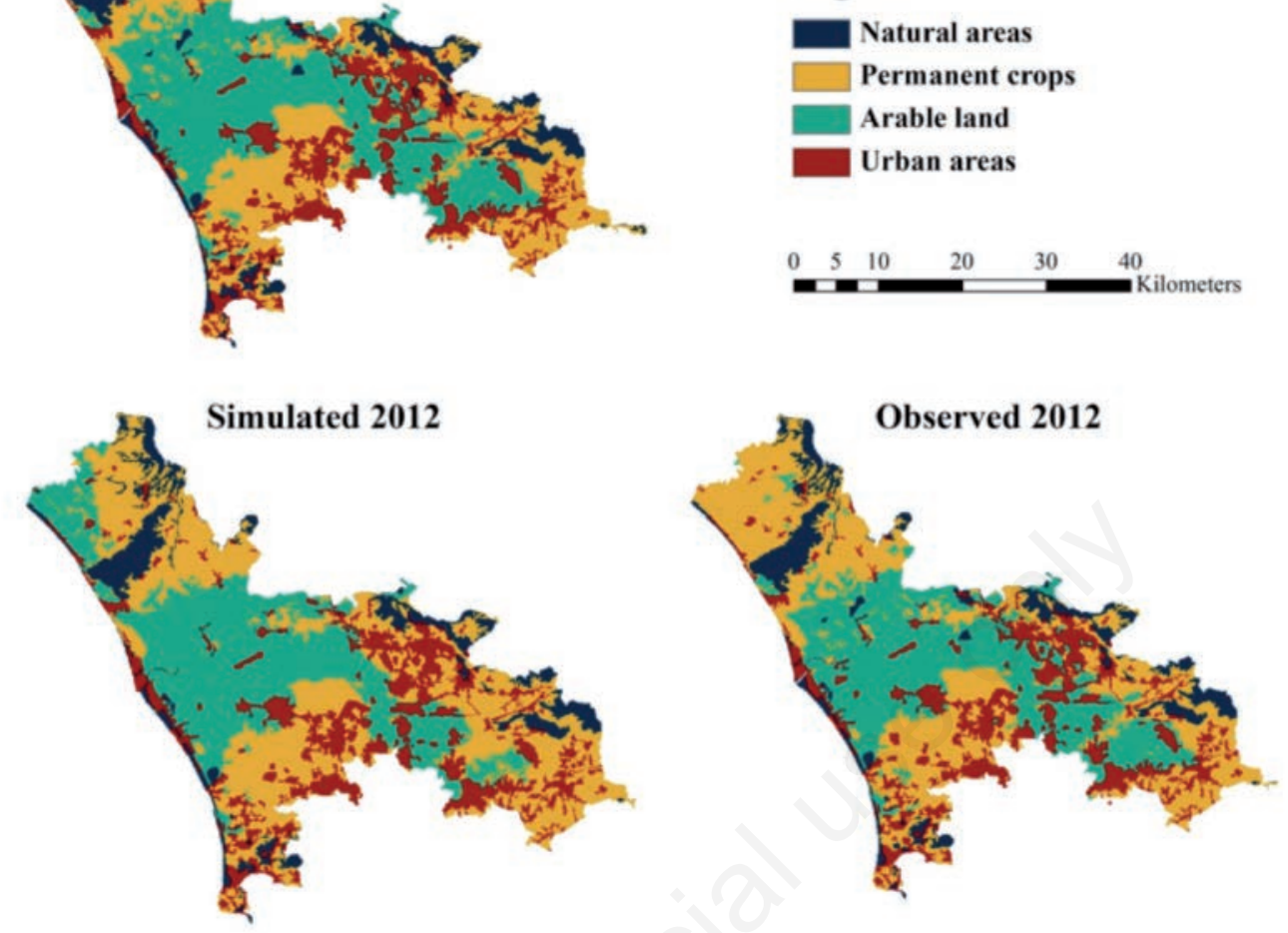

Figure 2. Simulation results from Dyna-Clue application, for the year 2012 compared to initial map of 2006 and observed map of 2012 from CLC. Grid-cell size is $100 \times 100 \mathrm{~m}$.

Table 2. Contingency table of land use change for scenario 1 and for the period 2012-2025. The unchanged areas are reported along the diagonal of the table. Areas changed in other classes are reported along the rows. Columns report the gain for each land use class. Last row reports gains (+) and losses (-) for each class. In italics are unchanged areas.

\begin{tabular}{lccccc} 
2012/2025 (ha) & Natural areas & Permanent crops & Arable land & Urban areas & Tot. 2025 \\
Natural areas & 14,814 & 344 & 7 & 12 & 15,177 \\
Permanent crops & 948 & 54,216 & 12,881 & 42 & 44,137 \\
\hline Arable land & 161 & 6524 & 35,499 & 834,228 & 31,089 \\
Urban areas & 458 & 1259 & 49221 & 28,538 & 28,686 \\
Tot. 2012 & 16,381 & 62,343 & -6993 & 2403 & 15,6631 \\
Differences & -1204 & 5794 & & & - \\
\hline
\end{tabular}

Table 3. Contingency table of land use change for scenario 2 and for the period 2012-2025. The unccopehanged areas are reported along the diagonal of the table. Areas changed in other classes are reported along the rows. Columns report the gain for each land use class. Last row reports gains (+) and losses (-) for each class. In italics are unchanged areas.

\begin{tabular}{lcccccc} 
2012/2025 (ha) & Natural areas & Permanent crops & Arable land & Urban areas & No-food crops & Tot. 2025 \\
Natural areas & 15,399 & 604 & 22 & 18 & 0 & 16,043 \\
Permanent crops & 534 & 52,341 & 11,956 & 438 & 190 & 65,269 \\
\hline Arable land & 54 & 5740 & 29,908 & 28,029 & 0 & 0 \\
Urban areas & 144 & 722 & 547 & 11 & 0 & 29,442 \\
\hline No-food crops & 250 & 2936 & 6788 & 28,686 & 0 & 9985 \\
Tot. 2012 & 16,381 & 62,343 & 49,221 & +756 & +9985 & 156,631 \\
\hline Differences & -338 & +2926 & $-13,329$ & & - \\
\hline
\end{tabular}


occurred from 2006 to 2012. Figure 4 shows comparison between land use observed in 2012 and simulated one for the same year. Table 2 reports contingency table for Scenario 1.

This scenario reports the expansion of urban areas that increase up to $8 \%$, covering about the $20 \%$ of the study area. The overall change in the study area involves the $15 \%$ of the total area. Urban growth will affect both natural and agricultural areas. This result was already observed in other study focused on the same study area (Cervelli et al., 2016).

\section{Scenario 2}

The phytoremediation scenario (Scenario 2) is aimed at introduction of new crops for reclamation of land with contamination or reduced fertility. This new class is supposed in competition with arable land and partially with permanent crops (Figure 5). Suitability map from Cervelli et al. (2016) was used as a proxy for the spatial allocation of new crops.

Table 3 shows the land use changes within the study area. Future land-use demand in this scenario is supposed to be one third of the overall change reported for the period 2006-2012. About 10,000 ha of no-food crops are introduced.

Main effect of the introduction of reclaiming strategies in the

a. Comparison Simulated/Observed

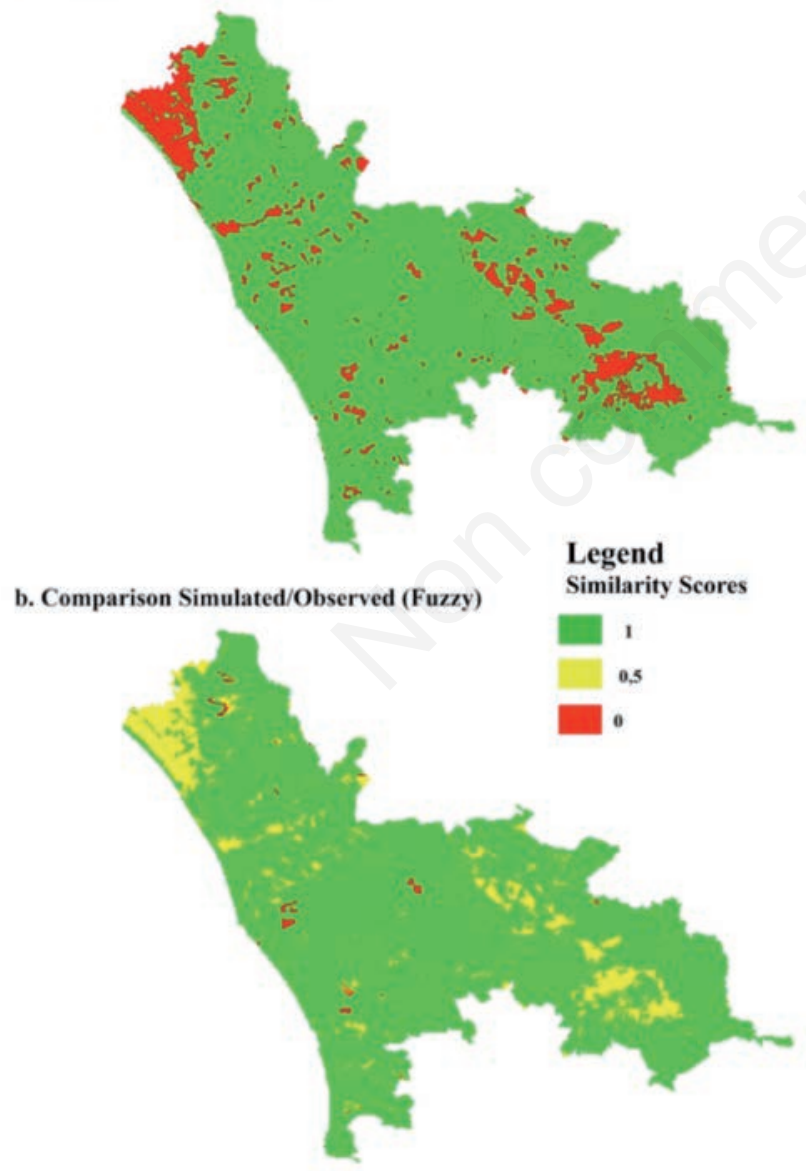

Figure 3. Map similarity between simulated and observed maps: a. Absolute: Kappa statistic; b. Fuzzy Logic: Kappa simulation; Similarity scores range between 0 (fully distinct) and 1 (fully identical) to express similarity of the cell. The value 0.5 can be deduced as considerably similar.

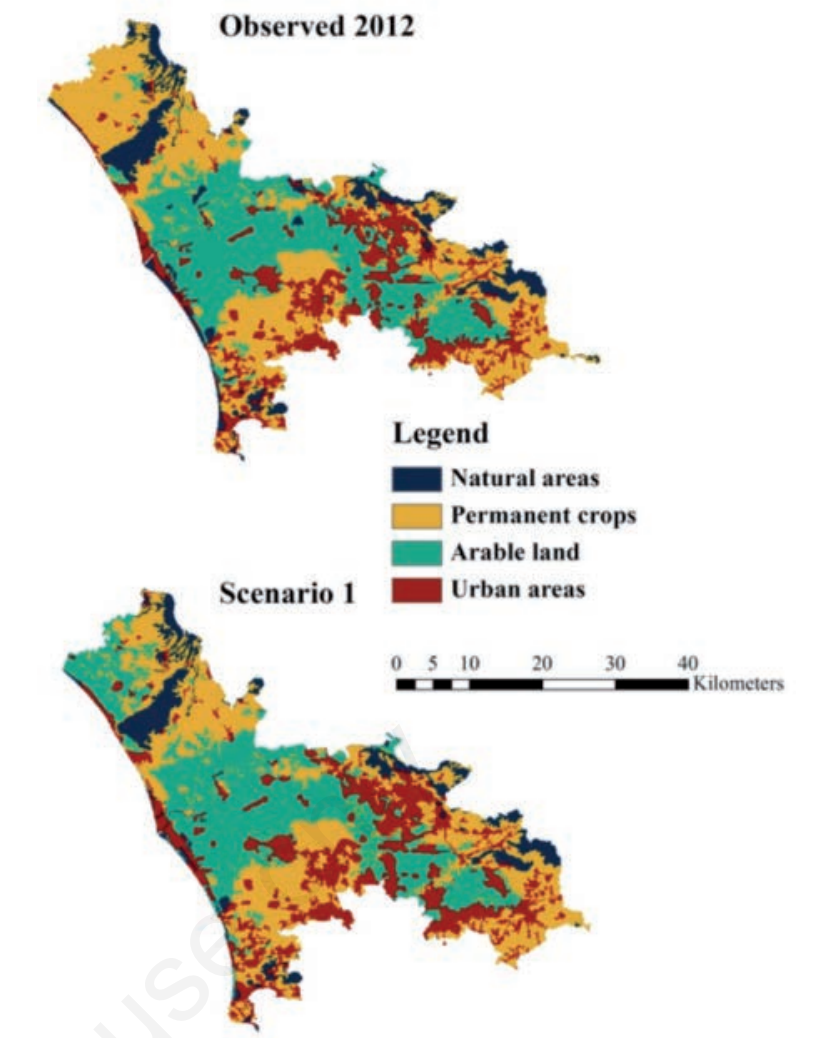

Figure 4. Comparison between land use observed in 2012 and simulated for the year 2025 (scenario 1).

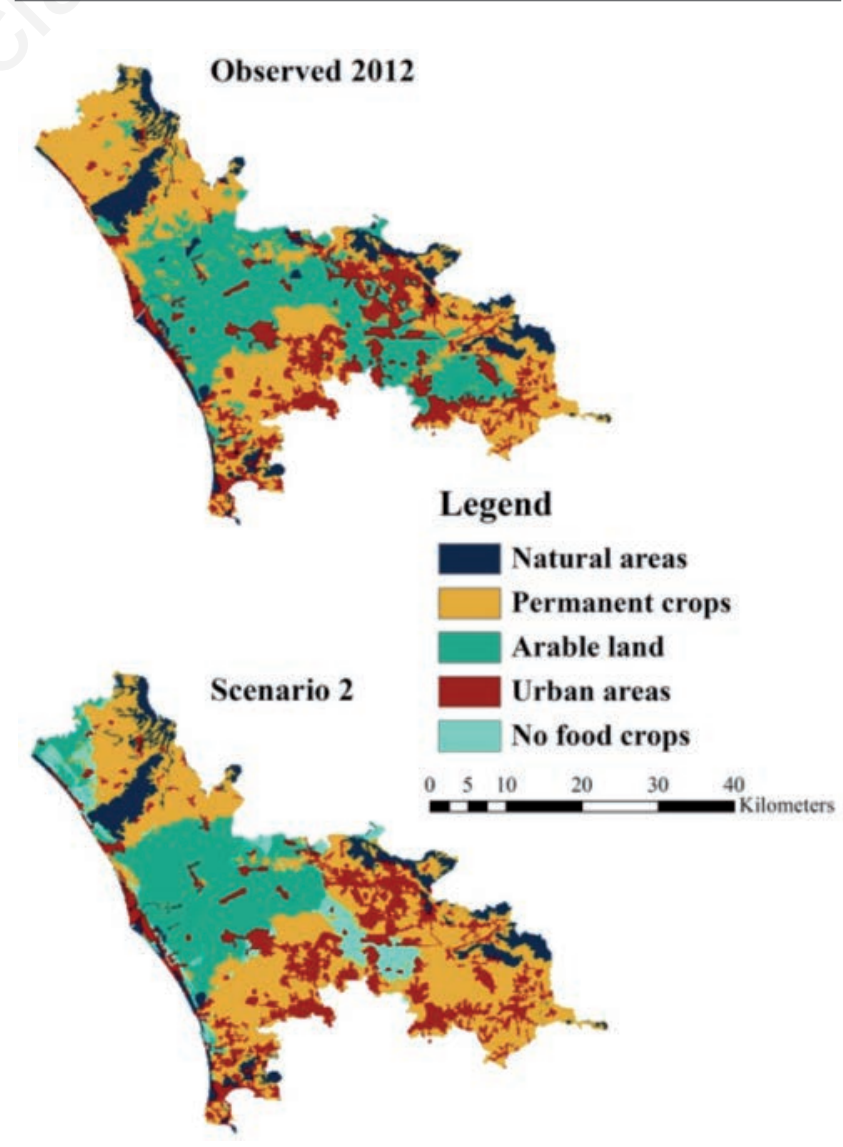

Figure 5. Comparison between land cover observed in 2012 and simulated for the year 2025 (scenario 2). 
study area is supposed to be the reduction of urban growth. As a matter of fact in this second scenario, urban areas grow only up to the $3 \%$, and also natural areas reduction $(-2 \%)$ is slowed down by the introduction of no-food crops in the study area. Regarding agricultural areas, a continuous but less intensive increase of permanent crops has been supposed, whereas arable land registers a drastic reduction following the introduction of no-food crops, as expected. Even if transformation from urban areas into other classes was supposed irreversible, a small change in this direction is sorted out from the simulation. This transformation is negligible as it represents only the $0.07 \%$ of the total study area, confirming the goodness of contingency table.

\section{Discussion}

Results of validation, calculated through the application of Kappa simulation algorithm, showed an overall good capability of the model in the interpretation of reality, although highlighting some critical issues that have to be more investigated.

The comparison of the land use in 2012 and that of 2025 in scenario 1 showed a general tendency to built-up areas expansion, with an increase of about 2400 ha, representing around $1.5 \%$ of the whole area, at the expense of agricultural land and those covered by natural vegetation. The analysis also shown that the structure of land uses foreseen in the scenario 1 would assume also a spatial conformation significantly different from the one of 2012 .

The comparison of the land use in 2012 and scenario 2 showed a situation where the expansion built-up areas is significantly lower than the one of previous scenario, affecting approximately 750 ha, which represents around $0.5 \%$ of the whole area. Moreover, the introduction of no-food crops on about 10,000 ha, i.e. about $6.8 \%$ of the whole area, would result in a significant decrease of arable land and a lower decrease of permanent crops, respectively equal to 6800 ha and 2900 ha. For the few hundred remaining ha, alternative crops would essentially replace surfaces covered with natural vegetation. As it occurred in scenario 1, also the arrangement of land uses foreseen in the scenario 2 would assume a spatial conformation significantly different from the one of 2012 .

\section{Conclusions}

Land use change models have the power of showing main effects of the application of specific intervention policy, projecting them for long-term period, or what will be either in the case of not interventions (Hewitt and Escobar, 2011). This study has highlighted the potential of predicting land use changes models as tools for decision support, considering a wide range of different factors: biophysical and socio-economic factors, but all concurring, with different weights, to determine the LUC. Nevertheless, even in this case, it was demonstrated that the ability of these tools to represent reality depends to a large extent on data availability, the reliability of the prediction depending mainly by the quality of the existing land use maps. All European studies are based on the CLC, which however has some limitations (Hewitt and Escobar, 2011). In this study we also used CLC, to be comparable with other European studies (Hewitt and Escobar, 2011). The mismatching between agricultural areas and permanent crops reported in the results section, as to be attributable to some misinterpretations in CLC, as demonstrated by the different classification reported for the same areas, in the land use map of Campania region (CUAS map). The use of CUAS map was tried to verify the reliability of the model and to improve the performance of our assessments. Results were encouraging and demonstrate the goodness of driving forces analysed.

A way to evaluate spatial allocation of energy crops is here suggested, different from the methodology proposed by Hellmann and Verburg in 2011. In their study energy crops were included in agricultural areas, whereas multi-criteria decision analysis was used to allocate only processing plants. In this study suitability map was used to substitute location characteristic that are very hard to determine for crops not already cultivated in the study area. In this way it is possible to isolate new crops introduced, improving the unavoidable land use change impact evaluation, especially in the case of impact on wildlife, that is very site-specific.

Finally from the comparison of the class 4 (no-food crops) of second scenario, with areas assessed from suitability map, it is evident an overlapping of about $87 \%$, delineating which areas will change for first, improving results from multi criteria analysis.

\section{References}

Agarwal C., Green G.M., Grove J.M., Evans T.P., Schweik C.M. 2002. A review and assessment of land-use change models: dynamics of space, time, and human choice. Gen. Tech. Rep. NE-297. Newton Square, PA: U.S. Department of Agriculture, Forest Service, Northeastern Research Station. 61 p. Available from: http://www.nrs.fs.fed.us/pubs/gtr/gtr_ne297.pdf Accessed: May 2016.

Capolupo A., Pindozzi S., Okello C., Fiorentino N., Boccia L. 2015. Photogrammetry for environmental monitoring: the use of drones and hydrological models for detection of soil contaminated by copper. Sci. Total Environ. 514:298-306.

Cervelli E., Pindozzi S., Capolupo A., Okello C., Rigillo M., Boccia L. 2016. Ecosystem services and bioremediation of polluted areas. Ecol. Eng. 87:139-49.

Cervelli E., Pindozzi S., Sacchi M., Capolupo A., Cialdea D., Rigillo M., Boccia L. 2017. Supporting land use change assessment through Ecosystem Services and Wildlife Indexes. Land Use Policy. 65C:249-65.

EEA (European Environment Agency). 2006. The thematic accuracy of Corine land cover 2000 - Assessment using LUCAS (land use/cover area frame statistical survey). EEA Technical report No 7. Available from: http://www.eea.europa.eu/publications/technical_report_2006_7 Accessed: October 2015.

Fiorentino N., Ventorino V., Rocco C., Cenvinzo V., Agrelli D., Gioia L., Di Mola I., Adamo P., Pepe O., Fagnano M. 2017. Giant reed growth and effects on soil biological fertility in assisted phytoremediation of an industrial polluted soil. Sci. Total Environ. 575:1375-83.

Gallego J. 2002. Fine scale profile of CORINE Land Cover classes with LUCAS data. In: European Commission (Ed.), Building Agro Environmental Indicators. Focusing on the European Area Frame Survey LUCAS. Vol. EUR Report 20521 EN. Available from: http://agrienv.jrc.ec.europa.eu/publications/ pdfs/LUCAS_CORINE.pdf Accessed: June 2016.

Giudicianni P., Pindozzi S., Grottola C.M., Stanzione F., Faugno S., Fagnano M., Fiorentino N., Ragucci R. 2017. Pyrolysis for 
exploitation of biomasses selected for soil phytoremediation: characterisation of gaseous and solid products. Waste Manag. 61:288-99.

Hagen A. 2003. Fuzzy set approach to assessing similarity of categorical maps. Int. J. Geogr. Inf. Sci. 17:235-49.

Hellmann F., Verburg P.H. 2011. Spatially explicit modelling of biofuel crops in Europe. Biomas. Bioenerg. 35:2411-24.

Hewitt R., Escobar F. 2011. The territorial dynamics of fast-growing regions: Unsustainable land use change and future policy challenges in Madrid, Spain. Appl. Geogr. 31:650-67.

Luo G., Yin C., Chen X., Xu W., Lu L. 2010. Combining system dynamic model and CLUE-S model to improve land use scenario analyses at regional scale: a case study of Sangong watershed in Xinjiang, China. Ecol. Complex. 7:198-207.

Malczewski J. 2006. GIS-based multicriteria decision analysis: a survey of the literature. Int. J. Geogr. Inf. Sci. 20:703-26.

Murray-Rust D., Brown C., van Vliet J., Alam S.J., Robinson D.T., Verburg P.H., Rounsevell M. 2014. Combining agent functional types, capitals and services to model land use dynamics. Environ. Modell. Softw. 59:187-201.

Panagos P., Borrelli P., Meusburger K., Alewell C., Lugato E., Montanarella L. 2015. Estimating the soil erosion cover-management factor at the European scale. Land Use Policy. 48:38-50.

Parker D.C., Manson S.M., Janssen M.A., Hoffmann M.J., Deadman P. 2003. Multi-agent systems for the simulation of land-use and land-cover change: a review. Ann. Assoc. Am. Geogr. 93:314-37.

Pindozzi S., Cervelli E., Capolupo A., Okello C., Boccia, L. 2016. Using historical maps to analyse two hundred years of land cover changes: case study of Sorrento peninsula (south Italy). Cartogr. Geogr. Inform. Sci. 43:250-65.

Pindozzi S., Faugno S., Cervelli E., Capolupo A., Sannino M., Boccia L. 2013. Consequence of land use changes into energy crops in Campania region. J. Agr. Eng. 44:467-71.

Pontius R.G., Schneider L.C. 2001. Land-cover change model validation by an ROC method for the Ipswich watershed, Massachusetts, USA. Agr. Ecosyst. Environ. 85:239-48.
Rykiel, E.J. 1996. Testing ecological models: the meaning of validation. Ecol. Modell. 90:229-44.

Saaty T.L. 2005. The analytic hierarchy and analytic network process for the measurement of intangible criteria and for decision-making. In: J. Figueira (Ed.), Multiple criteria decision analysis: state of the art surveys. Springer, New York, NY, USA, pp. 345-405.

Shoyama K., Yamagata Y. 2014. Predicting land-use change for biodiversity conservation and climate-change mitigation and its effect on ecosystem services in a watershed in Japan. Ecosyst. Serv. 8:25-34.

van Vliet J., Bregt A.K., Brown D.G., van Delden H., Heckbert S., Verburg P.H. 2016. A review of current calibration and validation practices in land-change modeling. Environ. Modell. Softw. 82:174-82.

van Vliet J., Bregt A. K., Hagen-Zanker A. 2011. Revisiting Kappa to account for change in the accuracy assessment of land-use change models. Ecol. Model. 222:1367-75.

Veldkamp A., Lambin E.F. 2001. Predicting land-use change. Agr. Ecosyst. Environ. 85:1-6.

Verburg P.H., Overmars K.P. 2009. Combining top-down and bottom-up dynamics in land use modeling: exploring the future of abandoned farmlands in Europe with the Dyna-CLUE model. Landscape Ecol. 24:1167-81.

Verburg P.H., Soepboer W., Veldkamp A., Limpiada R., Espaldon V., Mastura S.S. 2002. Modeling the spatial dynamics of regional land use: the CLUE-S model. Environ. Manage. 30:391-405.

Verburg P.H., Veldkamp A. 2004. Projecting land use transitions at forest fringes in the Philippines at two spatial scales. Landscape Ecol. 19:77-98.

Visser H., De Nijs T. 2006. The map comparison kit. Environ. Modell. Softw. 21:346-358.

Zhang P., He L., Fan X., Huo P., Liu Y., Zhang T., Pan Y., Yu Z. 2015. Ecosystem service value assessment and contribution factor analysis of land use change in Miyun County, China. Sustain 7:7333-56. 